\title{
Work Stress Perceived by Field Veterinary Functionaries of State Department of Animal Husbandry (SDAH) While Delivering Livestock Services in Haryana, India
}

\author{
Jayant Goyal", Mahesh Chander, Jitendra Pratap and Ajay Kumar Chaturvedani
}

Division of Extension Education, ICAR-IVRI, Bareilly-243122 (U.P.), India

*Corresponding author

\begin{abstract}
A B S T R A C T
The present study was conducted during 2016-17 to assess the work stress perceived by field veterinary functionaries (Sub-Divisional Officers, Veterinary Surgeons and

\begin{tabular}{|l|}
\hline Ke y w or d s \\
Field veterinarians, \\
Kruskal-Wallis, \\
SDAH, Work stress \\
\hline Article Info \\
\hline $\begin{array}{l}\text { Accepted: } \\
\text { 02 May } 2018 \\
\text { Available Online: } \\
\text { 10 June 2018 }\end{array}$ \\
\hline \hline
\end{tabular}
Veterinary Livestock Development Assistants) of Department of Animal Husbandry and Dairying, Haryana (DAH\&D). An ex-post facto research design was employed for the study. The study was restricted to 168 field veterinary functionaries of DAH\&D, selected from 4 districts i.e. Hisar, Karnal, Kurukshetra and Mahendergarh across Haryana. Data collection was done by using the questionnaire method. Majority of the respondents $(56.55 \%)$ were in medium level of work stress category followed by 30.36 percent and 13.10 per cent were in low and high level of work stress categories respectively. The work stress facets mean score shows, role ambiguity (2.21), constraint of change and rules regulations (2.18) and work overload (2.15) were the most prioritized stressors followed by role conflict (2.14), lack of cohesiveness among staff (2.13), job requirement-capability mismatch (2.13) and work difficulty (2.08). The result reveals that there was no clarity about the roles of the field professionals in the department and overburdened to perform developmental works, reports making and clerical work other than their core duties of providing livestock services to the farmers of the state.
\end{abstract}

\section{Introduction}

India hosts huge livestock wealth (512 million and 729 million of livestock and poultry population, respectively), accounting for $11.6 \%$ of world livestock population. But in terms of productivity and performance, India's livestock sector is one of the poorest in the World (Chander et al., 2010).

Reasons are varied like indiscriminate breeding, neglected health care, shortage of feed and fodder, lack of awareness among small farmers, poor guidance on good management practices, non-availability of appropriate technologies and ineffective delivery system (Hedge, 2012). But, the observed pattern of growth in crossbred dairy cows, improved breeds of buffalo, sheep, pigs and poultry as revealed by latest Livestock Census (2012) indicates a shift towards economically more efficient species. To exploit potential of the Indian livestock sector, there is a need of vibrant Animal Health 
Delivery System (AHDS) to sustain its productivity and viability (Bardhan, 2010).

State Department of Animal Husbandry (SDAH) is the major and primary livestock service provider mandated for livestock development in the state. Department of Animal Husbandry is responsible for providing health care and breeding facilities; preservation and protection of indigenous breeds, formulation of policies and programmes for animal husbandry. The responsibility for working out activities associated with implementation of schemes and programmes in the animal husbandry sector lies exclusively with the field staff viz. Deputy Directors, Chief Veterinary Officers (CVOs), Veterinary Officers (VOs) and Veterinary Assistants (VAs) working at the Government Veterinary Hospitals (GVHs) and dispensaries. Consequently, the responsibility and work load of an average field veterinarian has increased considerably and making the job of the veterinary personnel highly diversified. In such cases they are unable to maintain balance between the roles they are playing for livestock development in the state. Such disequilibrium leads to inadequate performance and work stress which could affect the productivity of the veterinarian. Thus, from the point of view of the organisation it has become vital to identify and prioritize the stressors that hamper the performance of field veterinary staff to imply remedial measure for making them more effective and efficient in delivery of livestock services.

\section{Materials and Methods}

The study was carried out on the field staff of State Department of Animal Husbandry, Haryana named as Department of Animal Husbandry and Dairying (DAH\&D). The data on the work stress was collected from field veterinary staff at three levels, differently viz. at Sub-Divisional Officer (SDO) working at Block level, from Veterinary Surgeons (VSs) posted on 5000 human population and Veterinary Livestock development Assistant (VLDA) on 3000 human population. A total of 168 field livestock service providers i.e. SDOs, VSs and VLDAs to the tune of 8,80 and 80 , respectively as a respondent were screened randomly from four randomly selected district (Hisar, Karnal, Kurukshetra and Mahendergarh) from the four administrative divisions (Hisar, Rohtak, Ambala and Gurugram) of the state. The primary data was collected personally by interviewing the respondent using a wellstructured and pre-tested instrument.

For the present study work stress was operationalised as the degree of stress physically or mentally respondent was experiencing while attending day to day departmental activities and delivery of livestock services. Work stress perceived by the respondents was assessed as per scale developed by Singh (1989) which composed of 7 stressor facets i.e. lack of cohesiveness among staff, role conflict, role ambiguity, work overload, constraint of change and rules regulations, work difficulty and job requirement-capability mismatch with 24 statements in total. Veterinary personnel were requested to give score for each stressor on a 4 point continuum as 'strongly agree (score of 4), 'agree' (score of 3), 'disagree' (score of 2) and 'strongly disagree' (score of 1) for positive statements and reverse for negative statements. The minimum and maximum scores that a respondent could obtain were 24 and 96. On the basis of total stress facets score respondents were classified into three categories viz. high, medium and low applying equal interval method. Further, mean score for each stressor facet was also calculated to prioritize different stressors perceived by veterinarians on different levels while rendering services to the farmers of the state. 


\section{Results and Discussion}

Socio-personal profile of field level Veterinary functionaries

Majority of VSs and VLDAs were within the age group of $35-50$ years $(48.75 \%$ and $43.75 \%)$ while two-third $(75 \%)$ of the SDOs was old in age (more than 50 years). The male female ratio was also extremely skewed in favor of males at all the levels, SDOs (100:0), VSs (92.50:7.50) and VLDAs (100:0). In terms of qualifications, two-third of the SDOs (75.0\%) was postgraduates, $90 \%$ of VSs were graduates and $10 \%$ were post-graduates whereas cent percent $(100 \%)$ of the VLDAs were holding diploma in Animal Husbandry without any post diploma education or degree. The average years of service experience for SDOs, VSs and VLDAs were 25.6, 16.3 and 17.0 years, respectively.

\section{Overall work stress for livestock service delivery}

The results on distribution of respondents according to their perceived overall work stress for livestock service delivery are presented in table 1 . The table indicates that within the pooled data, majority $(56.55 \%)$ of employees under study perceived medium level of stress followed by 30.36 per cent and 13.10 per cent under low and high level of stress categories. The study also depicts that majority $(58.75 \%$ and $56.25 \%)$ of grass-root level employee viz. VSs and VLDAs perceived medium level of stress followed by low (26.25\% and 32.50\%) and high (15.0\% and $11.25 \%$ ) stress categories, whereas majority $(50.0 \%)$ of SDOs recognized low stress followed by medium (37.50\%) and high $(12.50 \%)$ stress, while delivering livestock services in the study area.

Table 1 also shows that across the different levels of sampled work force there was no significant difference between the perceived work stress which was due to their posting in the field and confronted with the similar problems during livestock service delivery. But the slight variation was observed due to the difference in their service experience, their different hierarchical position and roles in the department, relationship with higher ups and peers, job autonomy and work load.

This findings are in line with study conducted by Sandika et al., (2007), Sankar et al., (2012), Goyal et al., (2014) and Patel et al., (2016) who also reported that majority of the respondents experienced moderate or medium level of job stress whereas, in conflict with Jain (2016) who reported that majority of the veterinary officers of Rajasthan perceived very heavy workload regarding delivery of livestock services.

Table.1 Distribution of respondents based on overall work stress

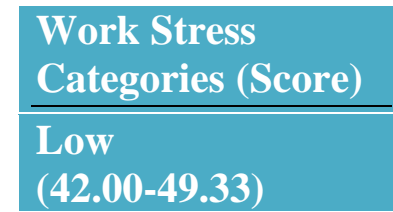

Medium

(49.34-56.66)

High

(56.67-64.00)

Mean \pm SD

\begin{tabular}{|c|c|c|c|c|}
\hline \multicolumn{4}{|c|}{ Field level Veterinary Personnel } & \multirow{2}{*}{$\frac{\text { Test Statistic }}{\text { Value }^{\sharp}}$} \\
\hline SDOs $(n=8)$ & VSs $(n=80)$ & VLDAs $(\mathrm{n}=\mathbf{8 0})$ & Pooled $(n=168)$ & \\
\hline $\begin{array}{c}4 \\
(50.00)\end{array}$ & $\begin{array}{c}21 \\
(26.25)\end{array}$ & $\begin{array}{c}26 \\
(32.50)\end{array}$ & $\begin{array}{c}51 \\
(30.36)\end{array}$ & 1.896 \\
\hline $\begin{array}{c}3 \\
(37.50)\end{array}$ & $\begin{array}{c}47 \\
(58.75)\end{array}$ & $\begin{array}{c}45 \\
(56.25)\end{array}$ & $\begin{array}{c}95 \\
(56.55)\end{array}$ & \\
\hline $\begin{array}{c}1 \\
(12.50)\end{array}$ & $\begin{array}{c}12 \\
(15)\end{array}$ & $\begin{array}{c}9 \\
(11.25)\end{array}$ & $\begin{array}{c}22 \\
(13.10)\end{array}$ & \\
\hline $49.0 \pm 6.0$ & $51.94 \pm 4.09$ & $51.40 \pm 4.39$ & $51.59 \pm 4.22$ & \\
\hline
\end{tabular}

Figures in parenthesis indicate percentage; ${ }^{\#}$ Calculated by Kruskal-Wallis $(\mathrm{H})$ test 
Table.2 Ranking of stress facets as perceived by SDAH personnel based on mean score

\begin{tabular}{|c|c|c|c|c|c|}
\hline \multirow[t]{2}{*}{ S. No. } & \multirow[t]{2}{*}{ Facets of Work Stress } & \multicolumn{4}{|c|}{ SDAH Personnel } \\
\hline & & $\begin{array}{l}\text { SDOs } \\
(\mathrm{n}=8)\end{array}$ & $\begin{array}{c}\text { VSs } \\
(n=80)\end{array}$ & $\begin{array}{l}\text { VLDAs } \\
(n=80)\end{array}$ & $\begin{array}{l}\text { Pooled } \\
(\mathrm{N}=168)\end{array}$ \\
\hline 1. & Lack of cohesiveness among staff & 1.92 (VII) & $2.14(\mathrm{VI})$ & $2.14(\mathrm{~V})$ & $2.13(\mathrm{~V})$ \\
\hline 2. & Role conflict & 2.05 (III) & $2.15(\mathrm{~V})$ & 2.15 (IV) & 2.14 (IV) \\
\hline 3. & Role ambiguity & 2.19 (II) & $2.21(\mathrm{I})$ & $2.21(\mathrm{I})$ & $2.21(\mathrm{I})$ \\
\hline 4. & Work overload & 1.95 (IV) & 2.18 (III) & 2.15 (III) & 2.15 (III) \\
\hline 5. & $\begin{array}{l}\text { Constraint of change regarding rules and } \\
\text { regulations }\end{array}$ & $2.38(\mathrm{I})$ & 2.19 (II) & 2.16 (II) & 2.18 (II) \\
\hline 6. & Work difficulty & 1.94 (VI) & 2.10 (VII) & 2.07 VII) & 2.08 (VII) \\
\hline 7. & Job requirement-capability mismatch & $1.96(\mathrm{~V})$ & 2.17 (IV) & $2.12(\mathrm{VI})$ & $2.13(\mathrm{VI})$ \\
\hline
\end{tabular}

Figures in parentheses indicates ranks

\section{Work stress facet score}

Various facets under work stress were ranked (Table 2) to ascertain their influence on the performance of SDAH employees for livestock service delivery in the state. Thus, it can be deduced that among the pooled data role ambiguity (2.21) is the foremost stressor perceived by SDAH personnel while delivering livestock services in the state followed by constraint of change regarding rules and regulations (2.18), work overload (2.15), role conflict (2.14), lack of cohesiveness among staff (2.13), job requirement-capability mismatch (2.13) and work difficulty (2.08). Sankar et al., (2013) also observed that role overload was perceived as the most important stressor dimension among the veterinarians of Kerala.

SDAH staff plays a major role in carrying out various developmental activities. They have been involved in treatment of animals and of late they have the additional responsibility of carrying out project work associated with implementation of multifarious schemes in the animal husbandry sector and other developmental sector in the village where they work. Consequently, responsibilities, expectations and expected behaviours for a position they hold create role ambiguity. Further, work load of average veterinary professionals has increased considerably and has to play more than one role. In such cases they are unable to balance the roles, which lead to inadequate performance for basic duties of livestock service delivery to the farmers.

In addition to this, lot of reports submission and paper work affect their major role of service delivery. Even some of the respondents flouted that they are not the veterinarians, rather a clerk. Thus from the above results, SDAH should acknowledge such stressors and make concrete efforts to mitigate their influence at the working place of field veterinary staff.

The measurement of work stress and its feedback plays an important role in knowing the efficiency of employees in an organisation. Any organisation, small or big needs constant studies and evaluation with a view to ascertain the measure necessary to improve its capacity to meet objectives it set forth. Field veterinary personnel play a key role in raising the livestock productivity and livestock development in the state by offering livestock services on the behalf of department of animal husbandry. So it becomes very essential to ascertain the level of work stress they perceive while rendering livestock services to the livestock owners of the state. In this study, field veterinary professionals of Haryana were involved in a survey about the prioritization of work stressors and the level of total work stress they perceived during delivery of livestock services. The 
finding of study shows that moderate stress perceived by the field veterinary professionals due to the ambiguous nature of work they have to perform in the field, consistent long working hours, excessive workload, conflict between field professionals at different levels, absence of rules and regulations for indiscriminate practices by quacks. So, administrators of the department should took urgent measures to identify strategies to improve the working conditions of veterinarians at the field with clear job activity chart, need for resources to assist and support field staff, regular trainings to brush-up their knowledge and to improve their skills for the quality and effective delivery of livestock services.

\section{Acknowledgement}

The authors are thankful to Director ICARIVRI, Bareilly for providing necessary facilities. The authors are also thankful to the all Field veterinary functionaries of DAH\&D, Haryana for their sincere responses.

\section{References}

19th Livestock Census. 2012. Department of Animal Husbandry, Dairying and Fisheries, Ministry of Agriculture, Government of India, New Delhi.

Bardhan, D. 2010. Factors influencing farmers' willingness to pay for animal health services and preference for private veterinary practioner. Indian Journal of Animal Sciences. 80(8): 790-97.

Chander, M., Dutt, T., Ravikumar, R.K. and Subrahmanyeswari, B. 2010. Livestock technology transfer service in India: A review. Indian Journal of Animal Sciences. 80(11): 1115-25.
Diksha, P., Devi, M.C.A., Dhodia, A.J., Parmar, S and Parameswaranaik, J. 2016. Role performance of the field extension functionaries in transfer of dairy technology in Karnataka. 8 (25): 1492-1495.

Goyal, J., Singh, K., Jha, S.K., Tiwari, M., Lal, S.P., Singh, M and Khanna, S.2015. Factors affecting job performance of veterinary surgeons in Haryana. Indian Journal of Dairy Science. 68(2): 185-189.

Hedge, N.G. 2012. Dairy Extension for transfer of technologies, Souvenir XL- Dairy Industry Conference, BAIF development research foundation.

Jain, A. K. 2016. A Study on Livestock Service Delivery System of State Department of Animal Husbandry in Tonk District of Rajasthan. M.V.Sc Thesis (Published), Rajasthan University of Veterinary and Animal Sciences, Bikaner, India.

Sandika, A.L., Angadi J.G., Hirevenkanagouda, L.V. and Basavaraj, H. 2007. A study on organisational climate perception by veterinary officers and veterinary livestock inspectors of the department of animal husbandry and veterinary service, Karnataka. The Journal of Agricultural Sciences, 3(2): 75-81.

Sankar, S., George, P.R. and Raj Kamal, P.J. 2013. Job satisfaction and stress among the veterinarians of Kerala state in India. Journal of Veterinary and Animal Sciences. 44: 31-34.

Sankar, S., George, P.R., Raj Kamal, P.J., Rajeev, T.S. and Mercey, K.A. 2013. Perception of veterinarians about organisational role stress. Journal of Life Sciences. 5(2): 139141.

Singh, S. 1989. Organisational stress and executive behaviour. Research Monograph. Shriram centre for industrial relations and human resources. New Delhi.

\section{How to cite this article:}

Jayant Goyal, Mahesh Chander, Jitendra Pratap and Ajay Kumar Chaturvedani. 2018. Work Stress Perceived by Field Veterinary Functionaries of State Department of Animal Husbandry (SDAH) While Delivering Livestock Services in Haryana, India. Int.J.Curr.Microbiol.App.Sci. 7(06): 47-51. doi: https://doi.org/10.20546/ijcmas.2018.706.007 